\title{
EHMTI-0136. Medical cannabis in the treatment of treatment-resistant, chronic cluster headache. A retrospective report
}

\author{
A Mosek*, M Dano, Y Fainmesser, Z Hybloom \\ From 4th European Headache and Migraine Trust International Congress: EHMTIC 2014 \\ Copenhagen, Denmark. 18-21 September 2014
}

\section{Background}

Treatment-resistant chronic cluster headache is a debilitating disease. Since 2011 we were able to offer cannabis and we hereby report our experience using cannabis in this condition.

\section{Methods}

A retrospective medical files analysis. The Institutional Review Board waived the need for informed consent.

\section{Results}

Out of 120 patients seen with cluster-headache since 2011, 31 (26\%) were diagnosed with chronic cluster-headache. Eighteen of them ( $78 \%$ men, average age $42.7 \pm 10$ years), were resistant to conventional treatments for cluster-headache and initiated cannabis treatment. The average duration of the chronic pain was $8.5 \pm 6$ years (range 2-28 years). Twelve of the subjects had 1-6, daily or near-daily, attacks. The rest had 1-4 weekly attacks. Background daily headache accompanied 7 of the patients.

Smoking was the preferred modality of cannabis usage (average 1 gram/daily, range 0.7-1.7 grams/daily). In an average follow-up of $1.8 \pm 0.8$ years ( 2 months- 3 years), cannabis usage resulted in $>50 \%$ decrease of the headache severity in $15(83 \%)$ patients, and in $90-100 \%$ severity decrease in $11(61 \%)$ subjects. Nine (50\%) patients reported $80-100 \%$ decrease in the headache frequency while the rest had no change in their attack frequency. Eleven patients (61\%) reported high satisfaction from cannabis usage, with significant reduction of medications; sleep and quality of life improvement. Somnolence and dizziness limited cannabis usage in 2 subjects. Treatment

\footnotetext{
The Headache Clinic Dep. of Neurology, Tel Aviv Sourasky Medical Center,
} Tel-Aviv, Israel

(c) 2014 Mosek et al; licensee Springer. This is an Open Access article distributed under the terms of the Creative Commons Attribution License (http://creativecommons.org/licenses/by/2.0), which permits unrestricted use, distribution, and reproduction in any medium, provided the original work is properly cited. success was unrelated to age, gender, duration of the headache or the chronic state.

\section{Conclusions}

Cannabis was found an effective treatment for resistant chronic cluster-headache, with minimal adverse-events.

No conflict of interest.

Published: 18 September 2014

doi:10.1186/1129-2377-15-S1-C46

Cite this article as: Mosek et al.: EHMTI-0136. Medical cannabis in the report. The Journal of Headache and Pain 2014 15(Suppl 1):C46. journal and benefit from:

- Convenient online submission

- Rigorous peer review

- Immediate publication on acceptance

- Open access: articles freely available online

- High visibility within the field

- Retaining the copyright to your article

Submit your next manuscript at $>$ springeropen.com treatment of treatment-resistant, chronic cluster headache. A retrospective

Submit your manuscript to a SpringerOpen ${ }^{\odot}$ 